\title{
Tecnura
}

\section{Teledetección aplicada al mapeo geomorfológico de los volcanes de la cuenca alta del río Chaschuil, provincia de Catamarca, Argentina}

\author{
Remote sensing applied to the geomorphological mapping of the volcanoes \\ of the upper Chaschuil river basin in the province of Catamarca, Argentina
}

\author{
Malvina Serra ${ }^{1}$, Carlos Gabriel Herrera $^{2}$, Adriana Ediht $\mathrm{Niz}^{3}$
}

Fecha de recepción: 3 de septiembre de 2018

Fecha de aceptación: 14 de febrero de 2019

Cómo citar: Serra, M., Herrera, C.G. y Niz, A.E. (2019). Teledetección aplicada al mapeo geomorfológico de los volcanes de la cuenca alta del río Chaschuil, provincia de Catamarca, Argentina. Tecnura, 23(60), 13-26. DOI: https://doi.org/10.14483/22487638.14642

\section{RESUMEN}

Contexto: La cuenca alta del río Chaschuil se encuentra en las provincias geomorfológicas de cordiIlera Frontal y sistema de Famatina, se extiende desde el límite superior de la cuenca, a los $26^{\circ} 45^{\prime} 6,35^{\prime \prime}$ de latitud $\mathrm{S}$ y $68^{\circ} 2^{\prime} 2215^{\prime \prime}$ de longitud $\mathrm{O}$, hasta el volcán Aguas Calientes, a los $27^{\circ} 13^{\prime} 25,81^{\prime \prime}$ de latitud $S$ y $68^{\circ} 19^{\prime} 548^{\prime \prime}$ de longitud O. La zona se inserta en el Cinturón de Fuego del Pacífico, que se caracteriza por concentrar algunas zonas de subducción más importantes del mundo, donde se genera una intensa actividad sísmica y volcánica.

Método: A través de operaciones estadísticas y numéricas aplicadas sobre los datos de las matrices que componen una imagen satelital, se generó la cartografía geomorfológica volcánica. Para dicho análisis, se utilizó el software libre SoPI 3.0, en el que se procesaron las imágenes satelitales Landsat 7 y 8 , de los años 2002 y 2015. La cartografía fue elaborada en el software libre QGIS 3.2.2, con el apoyo del software libre Google Earth Pro.

Resultados: Los mejores resultados del procesamiento digital se dieron en las bandas de rango visible y mediante distintas combinaciones de bandas en RGB. Se describen 13 aparatos volcánicos principales, altamente erosionados, con lavas pahoehoe asociadas; y erupciones secundarias, con lavas rugosas tipo aa sobrepuestas a las lavas más fluidas.

Conclusiones: La aplicación del procesamiento digital de imágenes satelitales es una herramienta óptima para el estudio de estructuras volcánicas, que permite su delimitación y clasificación.

Palabras clave: estructuras volcánicas, Landsat, procesamiento digital.

\footnotetext{
Licenciada en Geología. Investigadora del Instituto de Monitoreo y Control de la Degradación Geoambiental (IMCoDeG). Facultad de Tecnología y Ciencias Aplicadas. Universidad Nacional de Catamarca. San Fernando del Valle de Catamarca, Argentina. Contacto: malvinaserra@gmail.com ORCID: https://orcid.org/0000-0001-7127-7427

2 Ingeniero Civil. Magíster en Docencia Universitaria de Disciplinas Tecnológicas. Profesor Titular Cátedra Álgebra. Departamento de Formación Básica. Facultad de Tecnología y Ciencias Aplicadas. Universidad Nacional de Catamarca. San Fernando del Valle de Catamarca, Argentina. Contacto: cgherrera@tecno.unca.edu.ar ORCID: https://orcid.org/0000-0003-3292-4251

3 Licenciada en Geología. Doctora en Geología. Representante para Sudamérica en IUGS-GEM. Asesor sénior de la Unión Árabe de Geociencias (ArabGU). Directora del Instituto de Monitoreo y Control de la Degradación Geoambiental (IMCoDeG). Profesor Titular Cátedra Geomorfología. Facultad de Tecnología y Ciencias Aplicadas. Universidad Nacional de Catamarca. San Fernando del Valle de Catamarca, Argentina. Contacto: aniz@tecno.unca.edu.ar ORCID: https://orcid.org/0000-0002-3598-7111
} 


\section{ABSTRACT}

Context: The upper basin of the Chaschuil river is found in the geomorphological provinces of the Cordillera Frontal and the Famatina System; it extends from the upper limit of the basin $\left(26^{\circ} 45^{\prime} 6.35^{\prime \prime}\right.$ S $-68^{\circ} 2^{\prime} 22.15^{\prime \prime}$ O) to the Aguas Calientes volcano $\left(27^{\circ} 13^{\prime} 25,81^{\prime \prime}\right.$ S $\left.-68^{\circ} 19^{\prime} 5.48^{\prime \prime} \mathrm{O}\right)$. The zone is inserted in the Pacific Ring of Fire, which is characterized by concentrating some of the most important subduction zones in the world, where intense seismic and volcanic activity is generated.

Method: The volcanic geomorphological cartography was generated by statistical and numerical operations applied on the matrix data that make up the satellite image. For this analysis, the free software SOPI 3.0 was used to process the Landsat 7 and 8 satellite images of the years 2002 and 2015. The cartography was prepared using the free software QGIS 3.2.2 and Google Earth Pro.

Results: The best results of digital processing were given in the visible bands and by different combinations of bands in RGB. Thirteen main volcanic systems, highly eroded and with associated pahoehoe lavas, are described, as well as secondary eruptions with rugged aa-type lavas superimposed on the more fluid lavas.

Conclusions: The application of digital satellite image processing is an optimal tool for the study of volcanic structures, which allows their delimitation and classification.

Keywords: volcanic structures, Landsat, digital processing.

\section{INTRODUCCIÓN}

Las geoformas que se realzaron son típicas del ambiente volcánico, en el que se diferenciaron coladas de lava debidas a diferentes pulsos de efusiones volcánicas, teniendo en cuenta color y textura, tipo de estructuras volcánicas, litología, diseño de drenaje y demás rasgos de la geomorfología volcánica de la zona a estudiar. Este procesamiento digital de las imágenes satelitales permitió diferenciar las coberturas para realizar la cartografía geomorfológica correspondiente del área de estudio.

El clima de la zona del valle de Chaschuil es semiárido frío, temperaturas nocturnas inferiores a $0^{\circ} \mathrm{C}$ durante todo el año y gran amplitud térmica diaria; por encima de los 4500 m s.n.m. presenta evidencias de hielos permanentes, de tipo glaciar y nieves, glaciares de escombros, suelos congelados, permafrost, y en el área pedemontana domina la actividad eólica, tanto de acumulación como de deflación. Se sitúa al sur de la Puna austral, en el marco de la región de cordillera Frontal, y su relieve es típico de esta provincia geológica.
El área se ubica en el noroeste del departamento Tinogasta, al oeste de la provincia de Catamarca, dista 350 km de la capital catamarqueña. Como se observa en la figura 1, es un valle longitudinal que se extiende al oeste de Fiambalá, cabecera del distrito homónimo, y al que se puede acceder desde Tinogasta por la Ruta Nacional №. 60, hasta llegar al paso de San Francisco, que conecta Catamarca con la República de Chile.

La zona de estudio se extiende desde el límite superior de la cuenca del río Chaschuil, a los $26^{\circ} 45^{\prime} 6,35^{\prime \prime}$ de latitud S y 68 2'22 15" de longitud $\mathrm{O}$ (punto A), hasta el volcán Aguas Calientes a $\operatorname{los} 27^{\circ} 13^{\prime} 25,81^{\prime \prime}$ de latitud S y $68^{\circ} 19^{\prime} 548^{\prime \prime}$ de longitud $\mathrm{O}$ (punto B), considerado para esta investigación el sector sombreado en rosado en la figura 2, que corresponde a la cuenca alta del río Chaschuil.

El área se inserta en el Cinturón de Fuego del Pacífico, que se caracteriza por concentrar algunas de las zonas de subducción más importantes del mundo, donde se genera una intensa actividad sísmica y volcánica. Cuenta con sistemas montañosos superiores a los 6000 m s.n.m. en el sistema 


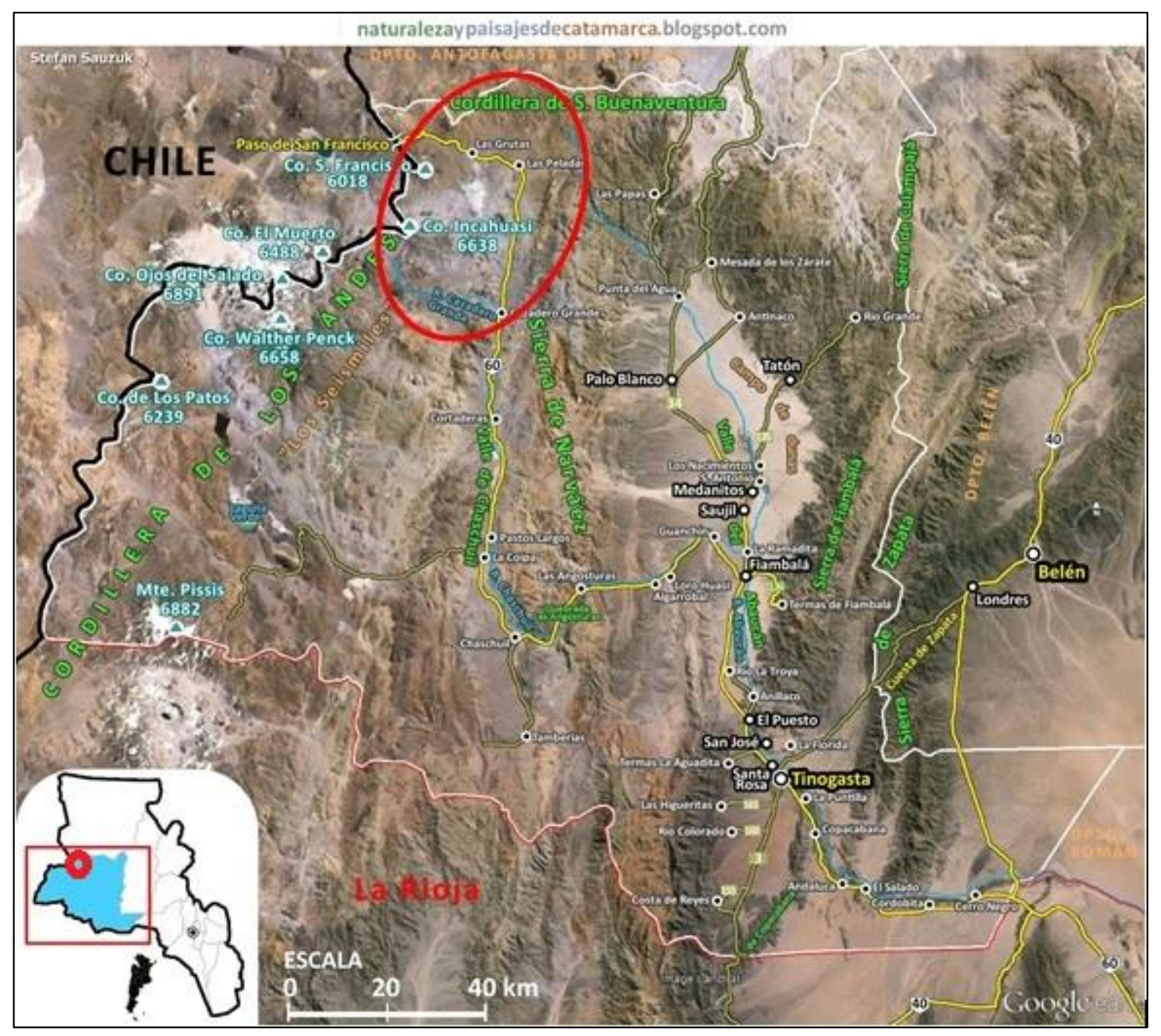

Figura 1. Ubicación y vías de acceso de la zona de estudio. Fiambalá, Catamarca, Argentina

Fuente: modificado de Sauzuk (s.f.).

andino, como lo son, los volcanes San Francisco e Incahuasi, y con estructuras volcánicas que superan los 5000 m s.n.m., como Bertrand, Pabellón, Chucula, Ojo de las Lozas, Morocho, etc.

Seggiaro (2006) particulariza a la región con una compleja evolución tectónica, ya que a la estructuración andina típica compresiva, de rumbo aproximadamente longitudinal, se le ha sobreimpuesto una dinámica transversal oblicua, con rumbo aproximadamente noroeste-sudeste a oeste-este, con un importante componente transcurrente. El primero ha sido responsable de la formación de valles tectónicos longitudinales, con dirección norte-sur y el segundo ha controlado la integración entre las diferentes cuencas endorreicas preexistentes y el desarrollo del volcanismo con posterioridad a la Fase Quéchuica, lo que provoca una alineación en la mayor parte de los aparatos volcánicos.

El objetivo del presente trabajo fue definir y describir la geomorfología volcánica, a través del procesamiento digital de imágenes satelitales, en la 


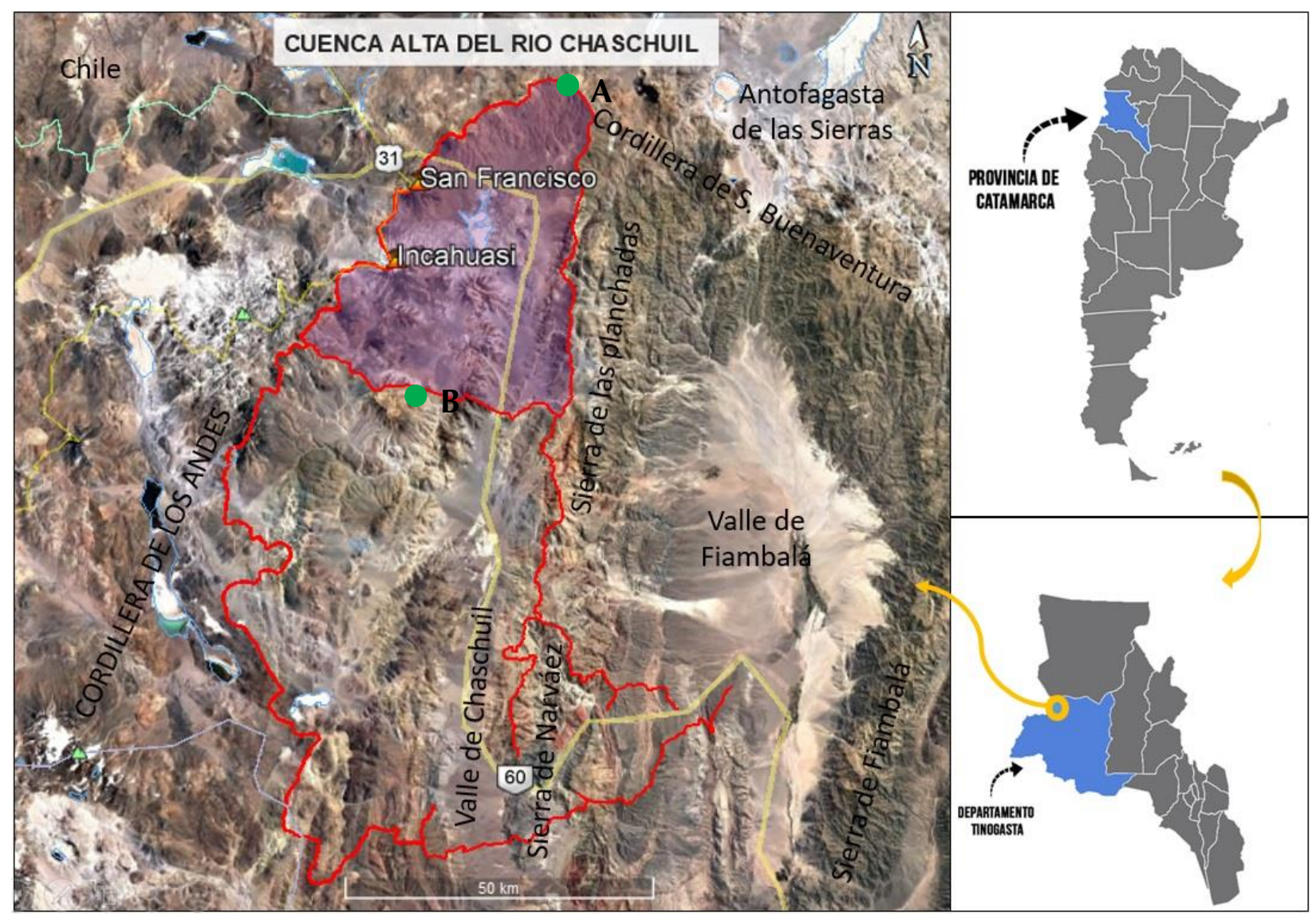

Figura 2. Croquis de la ubicación del área de estudio: cuenca alta del río Chaschuil. Fiambalá, Catamarca, Argentina

Fuente: elaboración propia.

cuenca alta del río Chaschuil, localidad de Fiambalá, para realizar la cartografía correspondiente y analizar la evolución de este ambiente.

\section{Región y asociación geomorfológica de la Cordillera Frontal}

Las Asociaciones Geomorfológicas se caracterizan por la recurrencia de elementos morfogenéticos endógenos y un mesoclima característico (Sayago, 1982). La Asociación Geomorfológica de la Cordillera Frontal (figura 3), en general, presenta un paisaje accidentado, definido por la presencia de relictos de estratovolcanes, fuertemente erosionados, que coexisten con los edificios volcánicos más altos que conforman el techo del mundo; en las áreas deprimidas se observa la formación de depósitos pedemontanos, de tipo abanicos y conos aluviales, algunos niveles de glacis de erosión. Las geoformas debidas a la acción glaciar más comunes son glaciares de escombros en las laderas de los volcanes con mayor acumulación de nieve.

En esta región se encuentran las nacientes de los afluentes principales del río Chaschuil y Guanchín -que a su vez es un afluente muy importante del río Abaucán-, como los ríos Cazadero Grande, Las Lozas, San Francisco, Las Peladas; en general el avenamiento está pobremente jerarquizado, el aporte hídrico proviene principalmente del deshielo y son frecuentes las surgencias naturales o vegas (Tezón, 


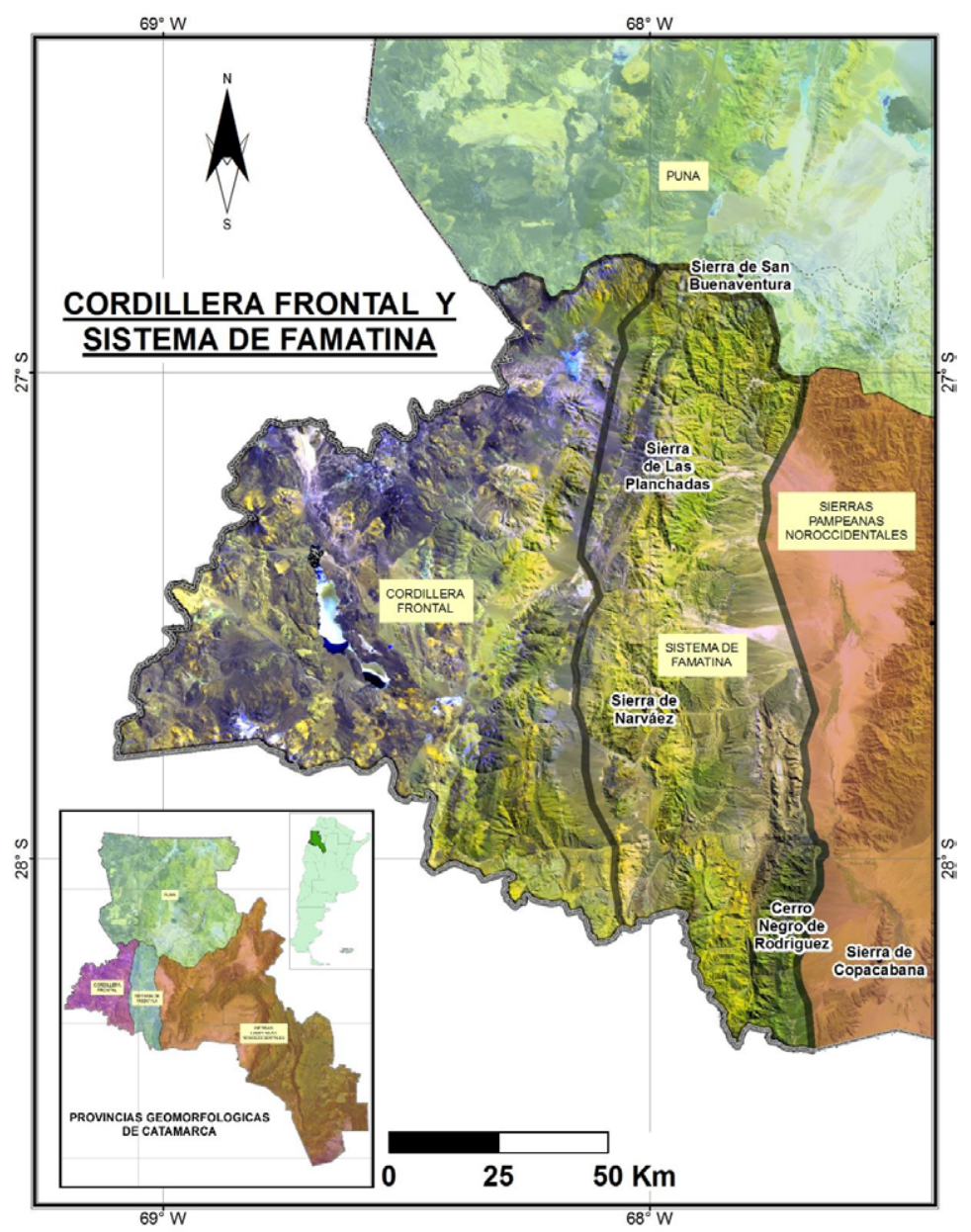

Figura 3. Región y Asociación Geomorfológica de la Cordillera Frontal, área de estudio delimitada con un óvalo rojo Fuente: Niz y Savio (2017).

1963). El conjunto conforma el valle de Chaschuil, el más representativo de esta región, situado por encima de los 3000 m s.n.m. (Niz y Savio, 2017).

\section{Volcanes}

Un volcán es una montaña que ha surgido por acumulación de productos emitidos desde el interior de la Tierra. Generalmente su forma es cónica y está construido alrededor del foco de emisión conectado con reservorios de roca fundida y gases, los cuales al ser expulsados contribuyen a su formación. Los fenómenos volcánicos, a diferencia de los emplazamientos de las rocas plutónicas, son manifestaciones en superficie de un evento subterráneo, y se caracterizan por su extrema rapidez. Los volcanes son la expresión morfológica superficial de un conjunto de fenómenos que se desencadenan durante la génesis, ascenso y erupción de magmas, con lo que se pueden generar formas positivas o negativas, dependiendo de la naturaleza de las erupciones y los procesos tectónicos, gravitatorios y erosivos sin y poseruptivos (Martí y Araña, 1993).

El término activo significa que el ser humano ha sido testigo ocular al menos de una erupción, es decir, cuando ha tenido una erupción en un lapso de años. El límite es arbitrario, aunque se considera un buen criterio el Holoceno (unos 10.000 años).

La mayoría de los volcanes presentan largos periodos entre una erupción y otra. Se dice entonces que 
el volcán está dormido; si no ha presentado actividad en tiempos históricos, está extinto. Estos términos son relativos, ya que un volcán que no ha presentado actividad en los últimos 5000 años podría entrar en erupción, al igual que uno que ha estado inactivo durante los últimos 25.000 años. En términos geológicos hay edificios que han sido activos durante 20 Ma, por tanto, el límite sería el Mioceno (unos 12 $\mathrm{Ma}$ ). Por otro lado, se considera que existe una erupción cuando hay un registro documentado.

En el área de estudio, si se analiza la dinámica de formación, teniendo en cuenta su ubicación y el ambiente tectónico en el cual se encuentra, sabiendo además que se trata de un vulcanismo basáltico continental, el proceso comienza y está condicionado a la geometría del plano de subducción, debido a que cuanto mayor es el ángulo (>25) se genera mayor fricción, lo que a su vez produce la fusión de la loza subductada, que al provocar fuertes gradientes térmicos se transforma a un estado semilíquido conocido como magma, este se acumula en dichos reservorios, y puede permanecer allí por más de un millón de años, hasta que las presiones son tales que la cámara magmática ya no puede contenerlo, y se libera, en forma fluida o explosiva, hasta llegar a la superficie en forma de lava y generar los aparatos volcánicos.

Posteriormente, a través del segundo proceso, de disminución brusca de gradiente de presión, permite explicar cómo se produjeron las erupciones en este sector, asociados a fallas profundas que conectan con la superficie sus lavas de composición básica; así, la fase volátil (fase estromboliana) es la causante de la emisión de material piroclástico durante la erupción.

\section{Estratovolcán}

Un estratovolcán es un tipo de volcán cónico y de gran altura. Como su nombre indica, está compuesto por múltiples estratos o capas de lava endurecida, que alterna con capas de piroclastos (lapilli y cenizas surgidos por una alternancia de épocas de actividad explosiva y de corrientes de lava fluida). Estos volcanes, caracterizados por un perfil escarpado y erupciones periódicas y explosivas, son los aparatos volcánicos principales que se encuentran en el área de estudio. Su erupción es del tipo fisural o hawaiana, con fases estrombolianas que son las que originan los conos de escoria.

En el caso de la zona de estudio, esta fase eruptiva estromboliana da origen a los edificios volcánicos que pueden estar constituidos por un único cono de escoria y una única colada; cuando es así se denominan volcanes monogénicos, de acuerdo con Llambías (2001).

\section{Cono cinerítico}

Se trata de una acumulación de escoria o cenizas, es decir materiales arrojados a poca distancia desde una chimenea, denominados por esta razón centralizados.

Se ha encontrado en la zona de estudio, una característica común a este vulcanismo basáltico, debido a su alto contenido en hierro, la coloración roja de muchas de las coladas y restos de lavas de las erupciones secundarias ha resultado ser interesante para su análisis.

Llambías (2009) aclara que, en primer lugar, este no se debe a un interperismo sino a una cuestión de enfriamiento del volcán. Explica que esta variación de las tonalidades de negro a color rojo se debe al grado de oxidación de las partículas microscópicas de hierro incluidas en el vidrio, reacción que tiene por efecto virar su coloración negruzca de origen, al rojo.

Russo (2010) identifica el mineral opaco de color negro como magnetita o ilmenita, por la elevada proporción de hierro, que causa el color oscuro de la roca y así mismo de la costra superior de lateración a modo de herrumbre (limonita).

Un caso particular es el cono desbocado o en herradura, donde el cono está abierto de un lado por un ensanchamiento del cráter. No es preciso atribuir esta disimetría ni a una explosión ni a una abertura de brecha debida a un derrame continuo de lava durante la erupción, sino más bien a un 
derrame continuo de lava durante la erupción que no ha permitido que las escorias se depositaran en el lado por donde transcurría la lava. Tales desbordamientos suponen una erupción corta con una actividad del tipo estromboliano y una emisión de lavas abundantes y fluidas. Llambías (2009) habla de conos aportillados, porque tienen forma de herradura debido a que la parte que falta ha sido arrastrada por la lava. Dentro del área se han encontrado numerosos ejemplos de ellos y son frecuentes en Antofagasta de la Sierra.

\section{Coladas de lava}

En primer lugar, es necesario aclarar la diferencia entre colada y lava; la primera corresponde al cuerpo de rocas resultante del enfriamiento de la lava, y la segunda se refiere al material fundido que fluye por la superficie.

A medida que la lava se enfría y se inmoviliza o libera gases expansivos y se vuelve espumosa, su viscosidad aumenta y el movimiento se vuelve perezoso. Por tanto, las distancias que recorre dependen de su fluidez, además condicionan su movilidad factores como: la temperatura (los basaltos son de mayor temperatura), el contenido de gases (es mayor en lavas ácidas) y la composición (porcentaje de sílice). En la figura 4 se observa la diferencia entre coladas según estos factores. Las lavas basálticas tienden a fluir libremente a lo largo de grandes distancias incluso por pendientes suaves antes de detenerse. El tamaño de las coladas depende del material emitido y de su viscosidad, siendo las erupciones de composición básica las de mayor superficie.

Según su aspecto superficial las coladas pueden ser:

- Pahoehoe o ropy lava o lavas cordadas.

- aa, block lavas o lavas en bloque o malpaís.

- Pillowlavas o lavas almohadilladas.

\section{METODOLOGÍA}

El trabajo comprendió tres etapas, que incluyeron tareas de gabinete y trabajos de campo complementarios: en la primera etapa se desarrollaron tareas de gabinete de recopilación y generación de información base; en la segunda, se llevaron a cabo trabajos de control de campo; y, por último, en la tercera etapa se realizó el procesamiento e interpretación de la información obtenida en las etapas previas.

En este estudio se utilizaron imágenes satelitales Landsat 7 y 8, correspondientes a los años 2002 y 2015. Para la obtención de imágenes satelitales se recurrió a las plataformas de descarga de imágenes USGS y CONAE, donde se obtuvieron imágenes del satélite Landsat (PATH-ROW = 232-079) adecuadas para cumplir con los objetivos de este trabajo.

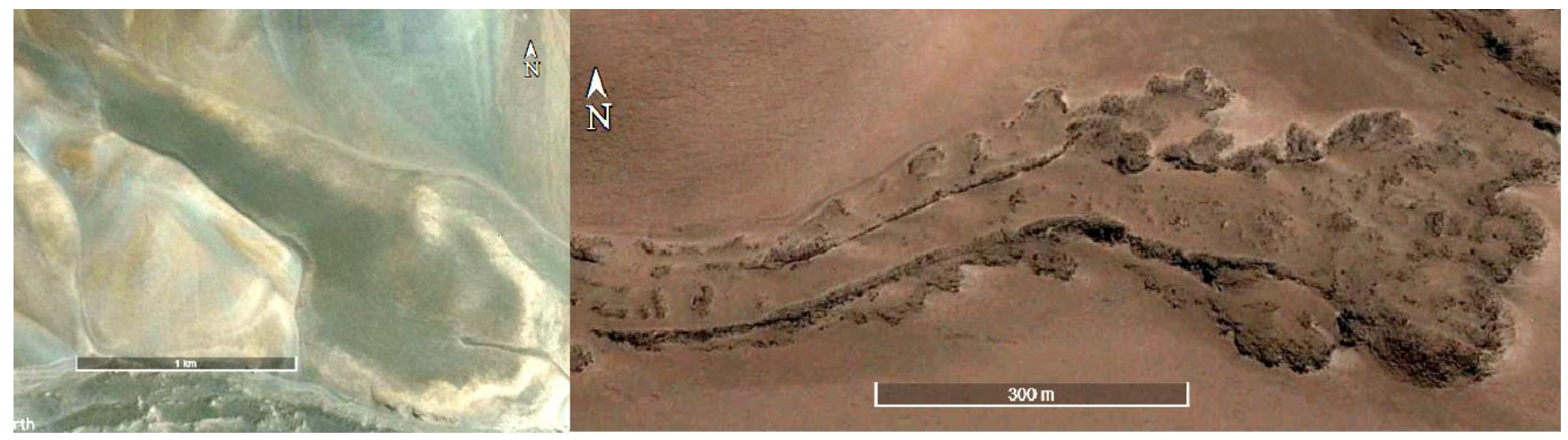

Figura 4. Aspecto superficial de las coladas de lava de la zona de estudio. Lavas tipo pahoeoe (izquierda) - lavas tipo aa (derecha)

Fuente: elaboración propia. 
Para el procesamiento digital de las imágenes obtenidas de la zona de estudio, se utilizó el software libre SoPI 3.0. Con la ayuda de este programa se realizó un recorte del área alrededor de los volcanes Incahuasi y San Francisco, georreferenciación, apilado de bandas, composición de color y clasificación no supervisada.

Posteriormente, se realizó un modelo digital de elevación (MDE) que permitió visualizar el relieve de las estructuras volcánicas principales, utilizando el software Global Mapper. Por último, con los resultados del procesamiento digital de las imágenes Landsat, se realizó la delimitación de las geoformas identificadas, mediante el software libre QGIS 3.2.2, en el que se insertó una imagen de alta resolución descargada de SAS.Planet. En QGIS se digitalizó la información y se elaboró la cartografía según la metodología ITC. El aspecto analítico del sistema ITC no solo es consistente con las principales tendencias de las leyendas existentes, sino que es universalmente aplicable para mapear en todas las escalas (Verstappen, 1983).

\section{Preprocesamiento}

En el caso de las imágenes Landsat, estas correcciones ya estaban resueltas, por lo que no fue necesario realizar para cada imagen una corrección geométrica y radiométrica. Aun así, se rectificó esta información mediante la georreferenciación de una imagen y con los puntos de control tomados en campo con GPS (sistema de posicionamiento global). El análisis anterior corroboró que las imágenes utilizadas se encontraban correctamente georreferenciadas y se procedió a transformar las coordenadas al sistema POSGAR 94 (Gauss Kruger - faja 2), con el software SoPI 3.0.

\section{Procesamiento digital}

Para la diferenciación de geoformas debidas a procesos volcánicos, se realizaron firmas espectrales, composiciones en falso color y una clasificación digital no supervisada.
Firmas espectrales. Para obtener la composición de color adecuada para el tipo de cobertura que se deseaba caracterizar, se elaboraron en primer lugar las firmas espectrales correspondientes a nieve, agua y roca, que permitieron diferenciar las coberturas según su respuesta espectral.

Composición de color. Se asignaron las bandas (longitudes de onda) a los tres canales disponibles R-G-B (rojo-verde-azul). Dado que el ojo distingue mucho mejor en tonos de rojo, es más eficiente visualizar la banda de mayor interés en el canal rojo. Por ello, en primer lugar, para diferenciar el hielo/nieve de la roca, colocamos el infrarrojo de onda corta $(1750 \mathrm{~nm})$ asociado al comportamiento del suelo, en el canal rojo; luego en orden de prioridad el infrarrojo cercano (865 nm), en el canal verde; y el verde $(655 \mathrm{~nm})$ al canal azul. Esta combinación se denomina falso color real (542). Para el estudio de la geomorfología y diferenciación de pulsos de lava, el mejor realce se observó en la combinación falso color 751. Para esta combinación, se asignó el infrarrojo de onda corta 2 (SWIR 2), al canal rojo; el infrarrojo de onda corta (1750 nm), al canal verde; y el azul, al canal azul.

Clasificación digital no supervisada. Los píxeles de la imagen fueron agrupados en conglomerados o clusters (clases), en función del valor de DN, asumiendo que sus características espectrales eran homogéneas; para lo cual se recurrió a la técnica K-Means. Posteriormente se asignó cada una de estas clases a componentes ambientales observados en el terreno como nieve, rocas, agua. Se hizo la clasificación no supervisada con 3 clases en 6 iteraciones, ya que se deseaba diferenciar nieve, rocas (distintos tipos de rocas) y agua; es decir, tres tipos de uso y cobertura. Esta clasificación permitió únicamente separar usos y coberturas muy disímiles entre sí, como los que se observaron en la zona investigada.

\section{RESULTADOS Y DISCUSIÓN}

Para el estudio de la geomorfología y diferenciación de pulsos de lava, el mejor realce se observó en la combinación de bandas falso color 751 para 
las imágenes de verano de 2002 (figura 5) y para las imágenes de verano de 2015 con la combinación de bandas 762 . El contraste de colores que se observa en la roca desnuda facilitó su diferenciación y permitió delimitar estructuras, coladas de lava y geoformas. Así mismo, las distintas tonalidades de verde/amarillo observables con esta combinación permiten discriminar qué coladas pertenecen a los aparatos volcánicos principales y cuáles a erupciones secundarias, ya que estas últimas muestran colores más claros por su composición ácida.

\section{Resultados cartográficos}

La cartografía fue exportada en tamaño A4 a escala 1:250.000 en coordenadas geográficas. En la figura 6 se muestra el mapa realizado, que permitió delimitar geoformas volcánicas y la superposición de coladas de lava.

\section{Distribución y nombres de los principales volcanes de la zona de estudio}

Los volcanes en la cuenca alta del río Chaschuil se encuentran distribuidos de dos maneras diferentes, según sean aparatos volcánicos principales o erupciones secundarias. Los primeros fueron numerados con la ayuda del MDE 3D, que permite apreciar los aparatos volcánicos. La numeración corrida va de 1 a 13; inicia al norte, en el volcán Chucula, y sigue con los volcanes que conforman el límite oeste de la cuenca hasta el volcán Aguas Calientes, donde continúa el conteo hacia el centro de la cuenca hasta el volcán Falso Morocho. No se observó la presencia de volcanes al este del valle de Chaschuil.

Para las erupciones secundarias, se ubican según lineamientos en sentido aproximadamente $\mathrm{E}-\mathrm{O}$, en el sector suroeste de la cuenca, donde conforman los volcanes monogénicos. También se mencionan en este apartado los conos parásitos.

Para una mejor organización del presente trabajo se va a dividir la descripción de los volcanes según sean principales o secundarios.

\section{Aparatos volcánicos principales}

Se han encontrado dentro del área la mayoría de las estructuras típicas del vulcanismo básico continental del tipo fisural con fases estrombolianas; allí se identifican coladas de lava aa, pahoehoe, conos, conos parásitos, bombas volcánicas, lapilli, conos cineríticos, cráter de volcanes con lagunas interiores, cráteres erosionados, etc.

En la zona de estudio los fenómenos erosivos son más lentos, generando geoformas comunes
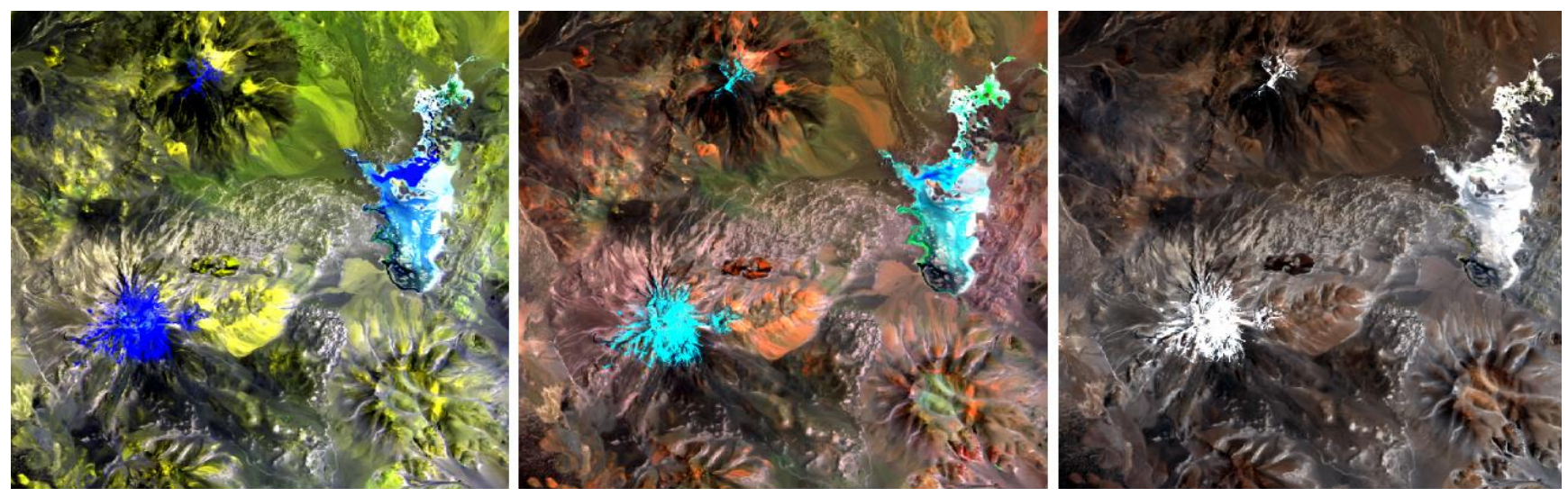

Figura 5. Distintas combinaciones de banda para la diferenciación de geoformas y litología volcánica en una imagen Landsat 7. Izquierda: TM 751; centro: TM 742; derecha: TM 321

Fuente: elaboración propia. 


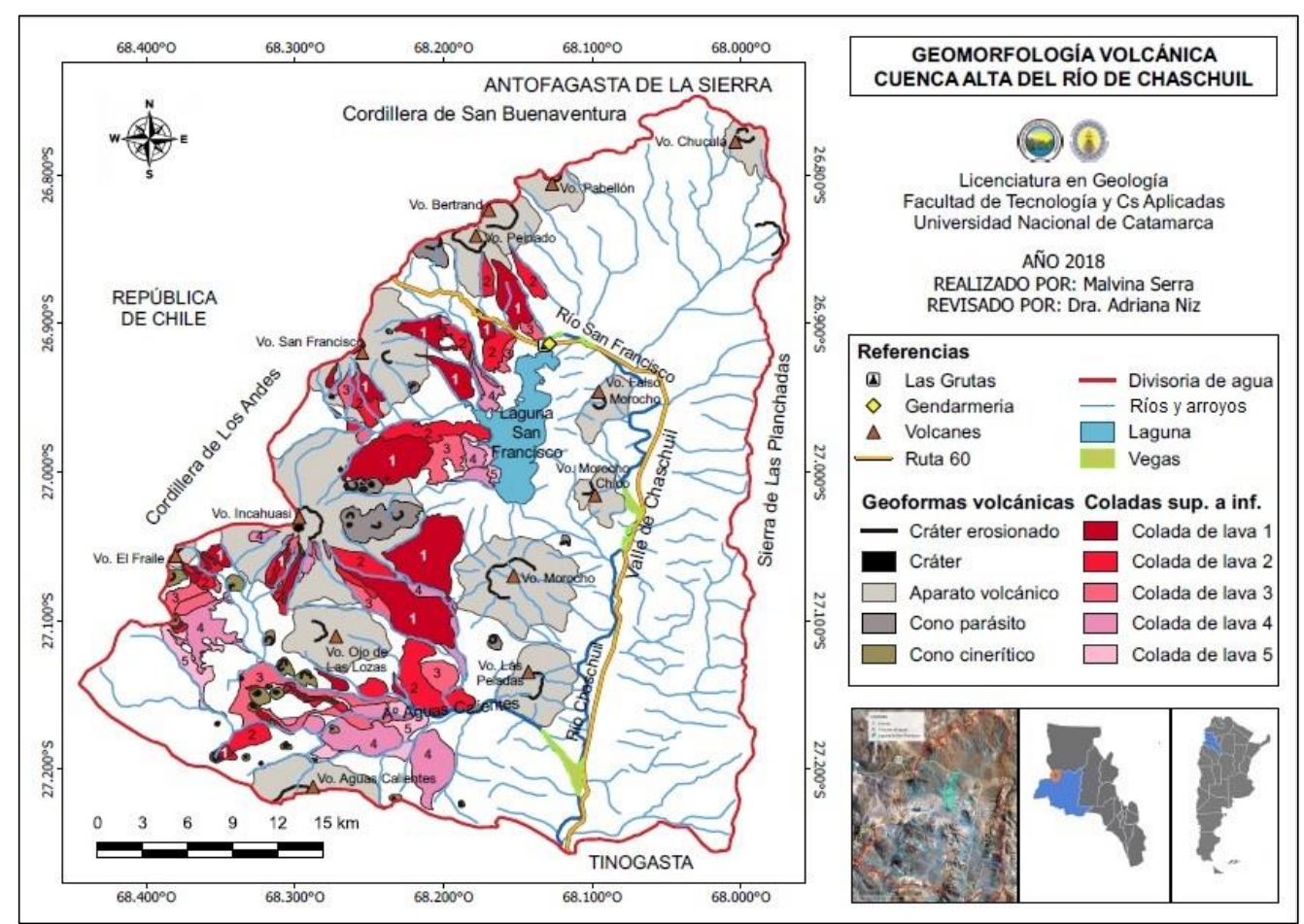

Figura 6. Mapa de geomorfología volcánica de la cuenca alta del río Chaschuil

Fuente: elaboración propia.

a estas regiones áridas. Estamos ante una morfogénesis larga, porque opera sobre construcciones volcánicas relativamente antiguas que no han sido perturbadas por nuevos paroxismos (es decir, nuevos periodos de actividad). Esas formas heredadas determinan el relieve volcánico. El modelado que actúa en estas rocas fue y es causado por procesos exógenos que van desfigurando las formas propiamente volcánicas y elaborando relieves morfoclimáticos (Russo, 2010).

Como se mencionó, en la figura 7 se han registrado un total de 13 focos efusivos principales en el área investigada, de los cuales se han diferenciado sus conos, cráteres y coladas de lavas asociadas.

Los aparatos volcánicos están orientados dentro del cuadrante noroeste-sudoeste y están relacionados principalmente con fracturas. Si bien, en la zona de estudio no se encuentran volcanes en actividad, observar hoy los vestigios de antiguas erupciones permite recrear el ambiente volcánico que dominó en épocas geológicas recientes el paisaje volcánico del Paso de San Francisco.

Al nor-noroeste de la cuenca se encuentran los volcanes Chucula (1), Pabellón (2), Bertrand (3) y Peinado (4). Estos poseen características similares por lo cual fueron agrupados. Son estratovolcanes de más de 5000 m s.n.m., presentan un cráter y cono altamente erosionado y sus coladas de lava son casi imperceptibles. El drenaje que desciende por sus laderas es radial y a la altura del Nick termina perdiéndose a través de cárcavas, que en algunos casos exponen ignimbritas y son evidencia de la neotectónica que actúa en la cuenca.

En el centro-oeste se encuentran los tres volcanes de mayor altura del área estudiada: Nevado de San Francisco (5), Incahuasi (6) y Nevado El Fraile (7), que constituyen el límite internacional con la República de Chile. Son estratovolcanes erosionados, en los que se distinguen entre las geoformas volcánicas: cono, cráter y coladas pahoehoe. Además, 


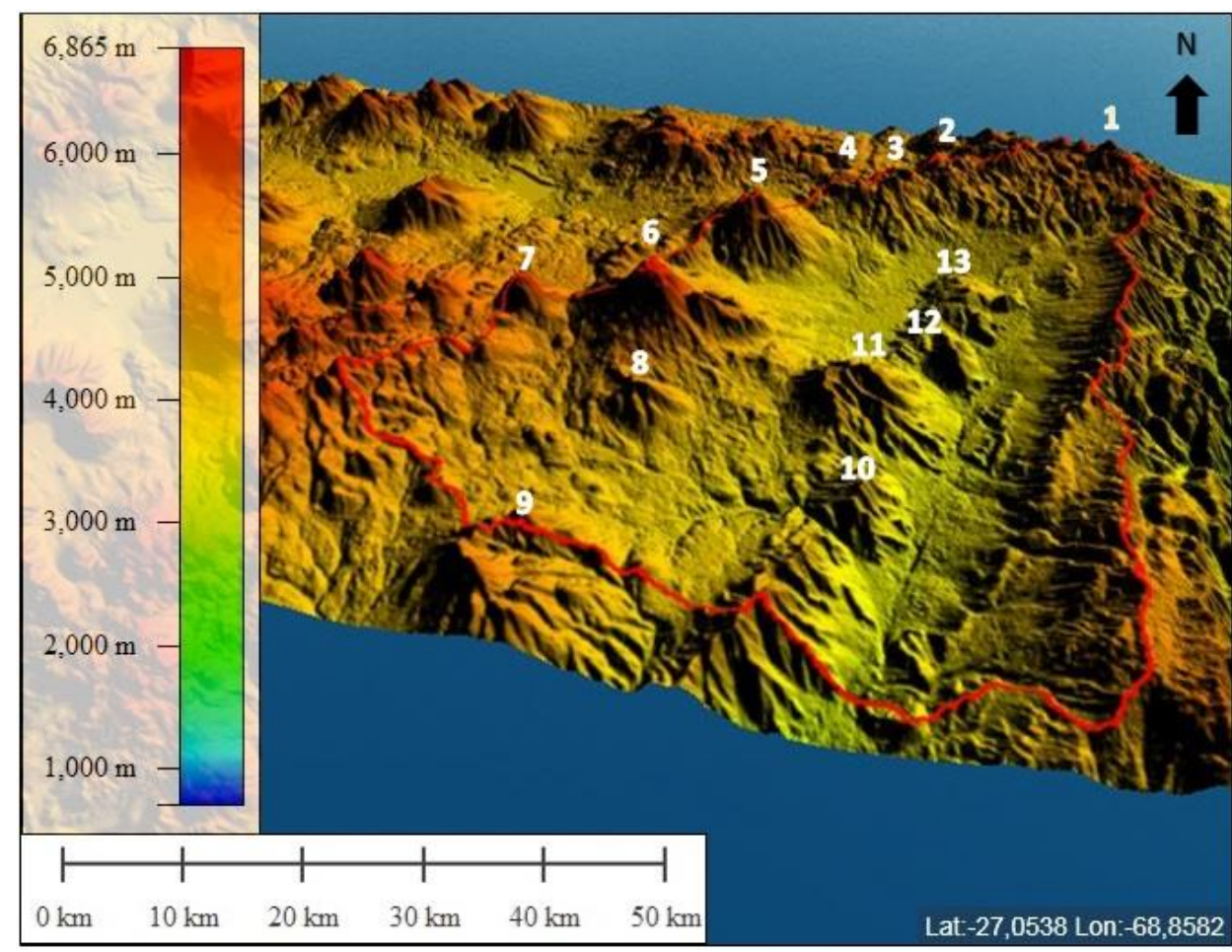

Figura 7. Modelo digital de elevación 3D (MDE). Identificación de aparatos volcánicos principales

Fuente: elaboración propia.

tienen numerosos conos parásitos que emitieron pulsos de lava tipo aa sobre coladas basálticas más antiguas. En las laderas y cumbres de estos volcanes, que superan los 6000 m s.n.m., hay vestigios de geoformas de un ambiente glaciar y periglaciar antiguo, se pueden describir circos glaciares, morrenas, drumlins, umbrales, glaciares de escombro, lagunas de deshielo, etc. Así mismo, en el modelado actual predomina la acción eólica, que acumula depósitos de arena en las depresiones de las coladas y en los conos parásitos principalmente.

Por último, en el sector sur-central de la cuenca alta del río Chaschuil se agrupan los volcanes Ojo de las Lozas (8), Aguas Calientes (9), Las Peladas (10), Morocho (11), Morocho Chico (12) y Falso Morocho (13). Poseen entre 4000 y 5000 m s.n.m. y son los menos desarrollados de la zona de estudio, prácticamente no se distinguen ni su cráter ni su cono, y las coladas de lava fueron erosionadas totalmente.
Los volcanes del área de estudio están asociados a un vulcanismo fisural con fases estrombolianas. Geomorfológicamente, el área se caracteriza por una cuenca terminal endorreica, típica de la Puna y Puna transicional, con amplias mesetas volcánicas y volcanes coronando el paisaje. La zona está conformada por aparatos volcánicos de gran altura y extensas coladas que cubren una vasta superficie. Las mesetas volcánicas corresponden a antiguas coladas, ya que se observa un grado de disección fluvial muy alta, lo que indicaría su antigüedad al compararlas con las superficies volcánicas contiguas de excelente conservación.

\section{Conos cineríticos}

En el sector suroeste de la cuenca se ubican a lo largo de lineamientos aproximadamente de dirección este-oeste, volcanes monogénicos de coloración más oscura que los principales (por presencia 
de hierro). Se distingue para estas efusiones, conos y cráteres definidos y coladas de lava más rugosas de tipo aa, que demuestran la evolución del magmatismo en el área hacia magmas más ácidos. Debido a que estas efusiones se encuentran mejor conservadas, fue posible diferenciar, con ayuda de imágenes satelitales, distintos pulsos de lava, discriminándose en la figura 8 hasta 5 emisiones superpuestas.

\section{Cono parásito}

Al igual que en los volcanes monogénicos, su coloración es oscura debido a la presencia de hierro y sus coladas de lava son de tipo aa, son las últimas manifestaciones derivadas de los volcanes principales, ubicadas en los conos muy erosionados y sobre coladas de tipo pahoehoe, como se observa en la figura 9.

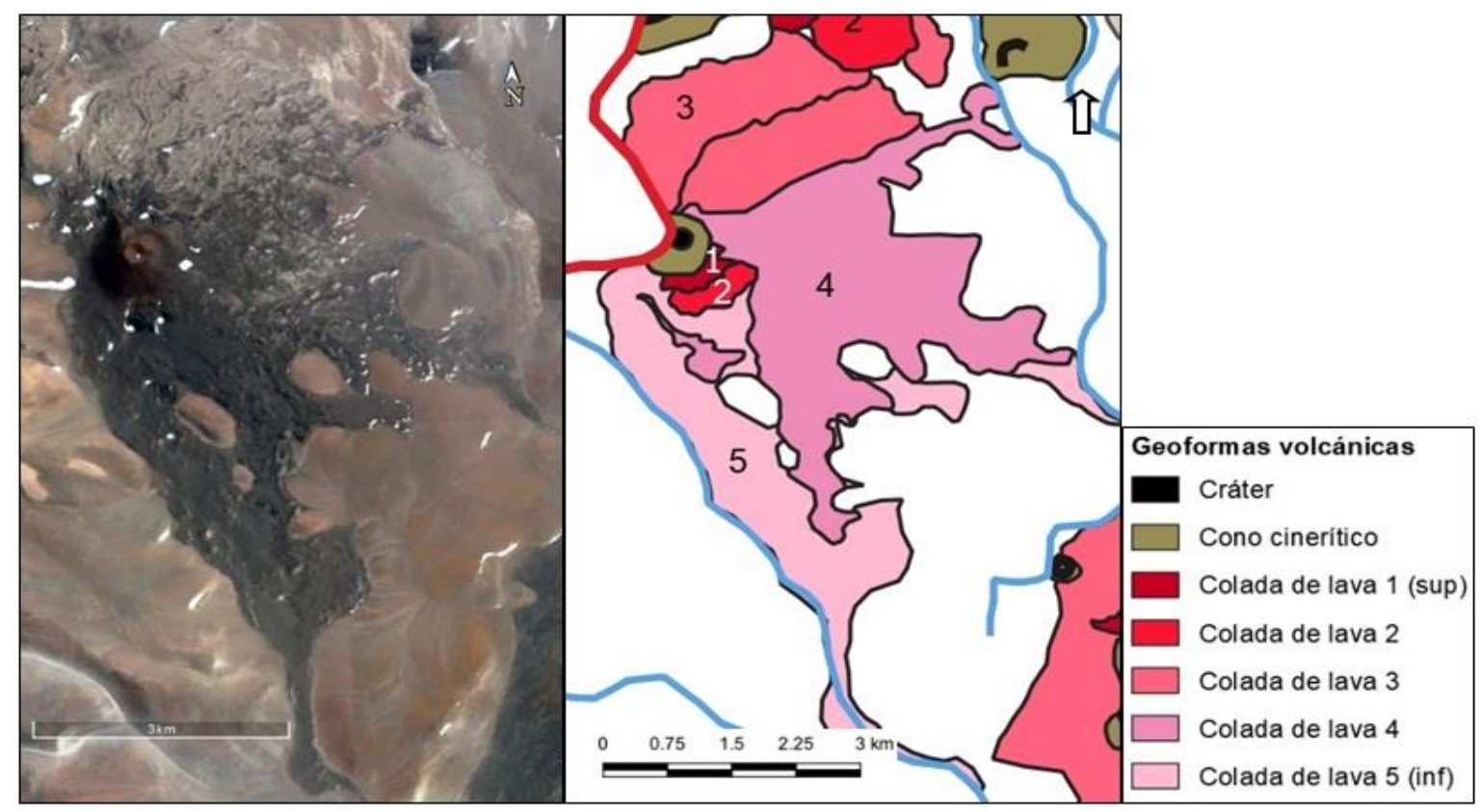

Figura 8. Vista en planta de un volcán secundario ubicado en el sector sur de la cuenca. Las coladas de lava fueron mapeadas en colores rojos-rosados, correspondiendo las más claras a las coladas más antiguas

Fuente: elaboración propia.
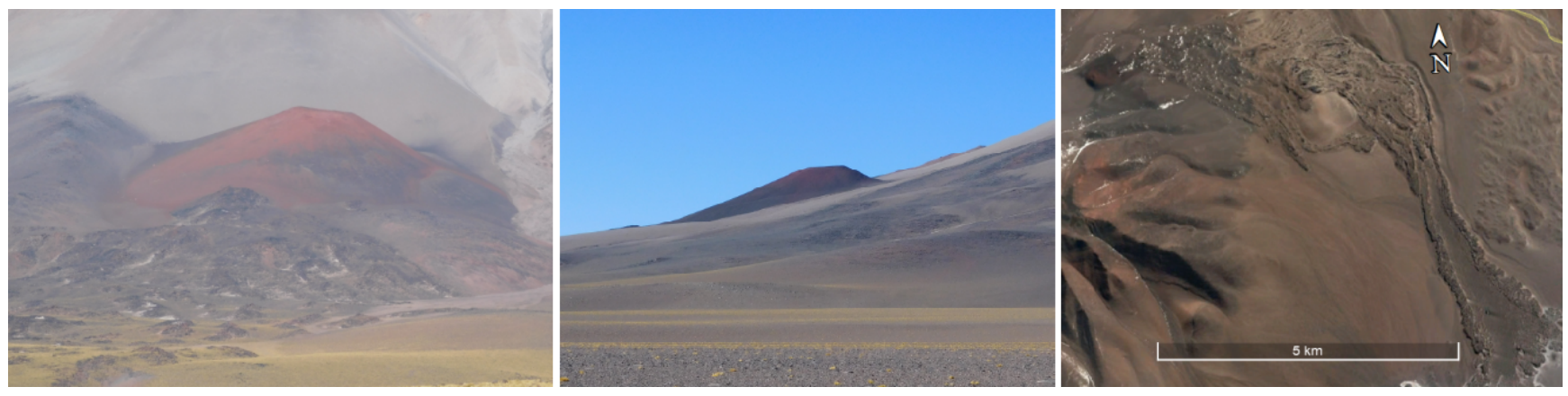

Figura 9. Distintas perspectivas de un cono parasito del volcán San Francisco

Fuente: elaboración propia. 


\section{CONCLUSIONES}

En el área de estudio, si se analiza la dinámica de formación, teniendo en cuenta su ubicación y el ambiente tectónico en el cual se encuentra y sabiendo que se trata de un vulcanismo basáltico continental, el proceso comienza y está condicionado a la geometría del plano de subducción, debido a que cuanto mayor es el ángulo (>25) se genera mayor fricción, lo que a su vez produce la fusión de la loza subductada, que al provocar fuertes gradientes térmicos se transforma a un estado semilíquido conocido como magma. Este se acumula en dichos reservorios, y puede permanecer allí por más de un millón de años, hasta que las presiones son tales que la cámara magmática ya no puede contenerlo, y se libera, de forma fluida o bien explosiva, hasta llegar a la superficie como lava, y formar los aparatos volcánicos.

Es evidente que la periodicidad de las erupciones se manifiesta en el sector estudiado, y permite plantear la hipótesis de que una gran cantidad de pulsos de emisión de lava han sido erupcionados durante las efusiones de los volcanes.

Aunque los magmas son mucho más viscosos que el agua, fluyen pendiente abajo, se concentran en canales y se ven detenidos por barreras topográficas que los obligan a adoptar superficies más o menos horizontales. Esta viscosidad tiene un límite elástico definido, pues las lavas se detienen al cesar la erupción, a diferencia del agua, que continúa su descenso pendiente abajo, aun cuando se interrumpa su abastecimiento.

Tal es el caso de los volcanes del área de estudio, siendo del tipo fisural o hawaiana con fases estrombolianas que son las que originan los conos de escoria.

Para los volcanes de la zona de estudio, el grado de explosividad es uno (1); en la escala, este valor es casi despreciable, la columna eruptiva de esta última no excede los 1000 metros. El grado de dispersión de las bombas volcánicas es un indicador de la explosividad dentro de estos grandes volcanes.
En el caso de la zona de este trabajo, esta fase eruptiva estromboliana construye los edificios volcánicos que pueden estar constituidos por un único cono de escoria y una única colada, cuando es así se denominan volcanes monogénicos.

Las geoformas volcánicas identificadas se ubican en el centro y oeste de la cuenca. Se describen 13 aparatos volcánicos principales, altamente erosionados y con lavas pahoehoe asociadas; y erupciones secundarias más recientes ubicadas a lo largo de lineamientos E-O, con lavas rugosas tipo aa sobrepuestas a las lavas más fluidas provenientes de los grandes estratovolcanes.

La aplicación del procesamiento digital de imágenes satelitales es una herramienta óptima para el estudio de estructuras volcánicas, lo que facilita su delimitación y clasificación.

Los mejores resultados del procesamiento de imágenes satelitales se dieron en las bandas del visible y mediante distintas combinaciones de bandas en RGB.

Para el estudio de la geomorfología y diferenciación de pulsos de lava, el mejor realce se observó en la combinación falso color 751 para las imágenes de 2002, y para las imágenes de 2015 con la combinación de bandas 762 .

\section{RECOMENDACIONES}

Si bien se han diferenciado en campo y a través del procesamiento de imágenes satelitales distintos niveles de coladas de lava, y en vista de que se presentan diversas litologías y estructuras volcánicas se recomienda mayores estudios para definir sus características petroestratigráficas. En este trabajo, de acuerdo con las combinaciones de banda y análisis visual realizado, se definen coladas básicas provenientes de erupciones de los estratovolcanes y coladas ácidas provenientes de erupciones secundarias.

Por último, este trabajo constituye un aporte a la propuesta que se está formalizando desde IMCoDeG, para incluir el valle de Chaschuil en las nominaciones para ser declarado Parque Nacional de Argentina. 


\section{FINANCIAMIENTO}

El presente trabajo de investigación fue realizado en el marco de las Becas de Estímulo a las Vocaciones Científicas-CIN 2016/7, que se encuadran en el proyecto "Caracterización geológica-geomorfológica y valoración de riesgos geoambientales en el área glaciar y periglaciar del valle de Chaschuil- Fiambalá- Catamarca", desarrollado en el Instituto de Monitoreo y Control de la Degradación Geoambiental- IMCoDeG.

\section{AGRADECIMIENTOS}

Al Instituto de Monitoreo y Control de la Degradación Geoambiental- IMCoDeG, donde se realizó este trabajo, y a la Agrupación de Montaña Calchaquí, por permitir concretar las campañas de campo.

\section{REFERENCIAS}

Llambías, E.J. (2001). Geología de los cuerpos ígneos (No. 552.3 LLA). Consejo Nacional de Investigaciones Científicas y Técnicas, Facultad de Ciencias Naturales e Instituto Miguel Lillo, Universidad Nacional de Tucumán.

\section{https://doi.org/10.25085/rsea.780101}

Llambías, E.J. (2009). Volcanes: nacimiento, estructura, dinámica. 1a. ed. Buenos Aires: Vázquez-Manzini Ed.

Martí J. y Araña V. (1993). La volcanología actual. Madrid: Consejo Superior de Investigaciones Científicas.

Niz, A. y Savio, M. (2017) "Geomorfología general de la provincia de Catamarca". En C. Muruaga y
P. Grosse (eds.), Relatorio Ciencias de la Tierra y Recursos Naturales del NOA (pp. 804-828). XX Congreso Geológico Argentino, San Miguel de Tucumán, Argentina.

https://doi.org/10.17485/ijst/2017/v10i7/111937

Russo, V. (2010). Caracterización y clasificación de las unidades geomorfológicas del ambiente volcánico de la cuenca media del río punilla. Antofagasta de La Sierra-Catamarca. [Tesis de grado]. Licenciatura en Geología, Facultad de Tecnología y Ciencias Aplicadas. Universidad Nacional de Catamarca, Argentina.

https://doi.org/10.24850/j-tyca-2017-06-05

Sauzuk, S. (s.f.). Cortaderas, departamento Tinogasta. [En línea]. Naturaleza y Paisajes de Catamarca. Recuperado de

http://naturalezaypaisajesdecatamarca.blogspot.com. ar/2014/11/Cortaderas-Tinogasta.html

Sayago, J.M. (1982). Las unidades geomorfológicas como base para la evaluación integrada del paisaje natural. Revista Geológica Lilloana, XVI(1), pp. 169-180.

Seggiaro, R.E. (2006). Hoja Geológica 2769-II- Paso de San Francisco. Boletín, 294, 1-62. Buenos Aires: Programa Nacional de Cartas Geológicas de la República Argentina-1:250.000.

Tezón, R.V. (1963). Texto explicativo del mapa hidrogeolégica de la República Argentina. Buenos Aires: Dirección Nacional de Geología y Minería.

Verstappen, H.T. (1983). Applied geomorphology: geomorphological surveys for environmental development. Amsterdam: Elsevier.

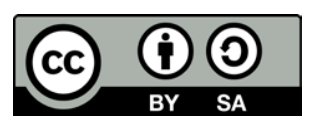

Tecnura • p-ISSN: 0123-921X • e-ISSN: 2248-7638 • Vol. 23 No. $60 \bullet$ Abril - Junio de $2019 \bullet$ pp. 13-26 